\title{
LA ORGANIZACIÓN FAMILIAR EN LAS ISLAS DE CABO
}

VERDE

Marta M. MAFFIA

UNLP/CONICET

“...la relación de familia en Cabo Verde es un asunto muy complejo”. (Zé, 71 años, nacido en São Vicente, Cabo Verde).

Resumen: En este artículo analizamos la organización familiar en las islas de Cabo Verde, archipiélago africano, situado frente a las costas de Guinea, Mauritania y Senegal.

Las tradiciones mediterráneas y africanas están presentes en la configuración familiar y en las relaciones al interior de la misma.

El modelo analítico de Klaas Woortmann, en conjunción con la noción de habitus de Pierre Bourdieu, nos permiten una mejor aproximación a la comprensión de la multiplicidad de representaciones y prácticas de la vida familiar caboverdeana.

Palabras clave: familia- parentesco- islas de Cabo Verde-

tradiciones mediterráneas y africanas

\section{Abstract}

The aim of this paper is to analyse the family organization in Cape Verde, an african archipelago located in front of the coasts of Guinea, Mauritania and Senegal. We state that the african and mediterranean traditions are actually present in the family organization and in the relationships that shape it. The analytical model of Klaas Woortmann and the concept of habitus from Pierre Bourdieu's theory, will allow us to better understand the varying representations and practices of family life in Cape Verde. Key Words : familiy- kinship-Cape Verdean island- african and mediterranean traditions.

Fecha de recepción del artículo: Septiembre de 2008

Fecha de evaluación: Octubre de 2008 
Résumé : Cet article vise à analyser 1' organisation familiale à Cap-Vert, un archipel africaine situé en face de Guinée, Mauritanie et Senegal. Nous soulignons le lien étroit entre les traditions africaines et méditerranées, et la organisation de la famille. Le modèle théorique de Klaas Woortman et la notion $\mathrm{d}^{\prime}$ habitus de Pierre Bourdieu, nous permettra d' analyser la diversité des réprésentations qui existent dans la vie familiale.

Mots-clé : Famille- parenté- Cap-Vert achipel -traditions africaines et mediterranées

\section{Cabo Verde}

Cabo Verde es un archipiélago africano en el Atlántico, frente a la costa de Guinea, Mauritania y Senegal, conformado por diez islas distribuidas en dos grupos: Barlovento, formado por las islas de Santo Antao, San Vicente, Santa Luzia, San Nicolau, Sal y Boavista, y Sotavento, que comprende las islas de Maio, Santiago, Fogo y Brava.

El archipiélago, que se encontraba deshabitado, fue descubierto por los portugueses entre 1456 y 1460, y colonizado con individuos provenientes del sur de Portugal, población a la que se sumaron numerosos africanos que fueron traídos del continente como esclavos: mandingas, jalofos, fulas-pretos y algunas más, fueron las principales etnías que dejaron mayores vestigios de su presencia, fundamentalmente en Sotavento.

Así Cabo Verde, constituido como un entrepuesto comercial de esclavos, donde además de portugueses también comerciaban holandeses, ingleses $\mathrm{y}$ franceses -quienes no reconocían el monopolio portugués- y posicionado en una situación estratégica en el Atlántico, recibió las más variadas influencias de los tres continentes: Europa, África y América.

La heterogeneidad racial, lingüística y cultural de los grupos que originalmente poblaron el archipiélago, el campo de relaciones generado por su situación estratégica (geográfica y comercial), la discontinuidad

1 El trabajo de campo fue realizado en Argentina, Portugal y Cabo Verde, particularmente en este último país, con períodos de distinta duración, en los años 1981, 1992 y 1996, con el apoyo del Conicet, de la Universidad Nacional de La Plata y del Ministerio de Negocios Extranjeros de la Rca. de Cabo Verde. 
territorial que hicieron de cada isla un compartimiento estanco, dieron por resultado la constitución de un nuevo grupo étnico, el caboverdeano.

Luego de más de quinientos años de dominio colonial, Cabo Verde junto a Guinea Bissau, logra independizarse de Portugal el 5 de julio de 1975.

Una conjunción de factores como los climáticos, prolongadas sequías y suelos volcánicos, el régimen de tenencia de la tierra, demográficos, entre otros, sumados a la política implementada por Portugal, rompe sistemáticamente el precario equilibrio de la economía caboverdeana y es en ese equilibrio inestable, en el que se configura el fenómeno migratorio caboverdeano, constituyéndose en un país estructuralmente expulsor de su población. Millares de hombres y mujeres emigran a lo largo de toda su historia, hacia distintas partes del mundo, la Argentina fue uno de esos destinos. ${ }^{2}$

Breves antecedentes sociohistóricos en relación a la organización familiar.

Para una mejor comprensión de la organización familiar caboverdeana y de la ideología patriarcal que sustenta, es necesario tener presente algunos aspectos de la organización/formación social y su evolución a través de los tiempos, ya que se trata de una sociedad basada en la vieja institución esclavista.

Cabo Verde no fue una prioridad para la corona portuguesa en cuanto a una colonización en sentido estricto, sino que para ella su valor radicaba en el punto estratégico en el océano Atlántico como parte de "la materialización del proyecto acumulativo expansionista" (Fernández,G. 2002:27). Esto determinó el perfil de los primeros pobladores, dejando de contar con el elemento femenino blanco para centrarse en el varón, situación que, sin lugar a dudas produjo una significativa repercusión en toda la estructura social caboverdeana, así como posteriormente lo hizo la emigración.

La estructura social del archipiélago comienza a configurarse a partir de una minoría dominante blanca (fundamentalmente hombres) y un grupo dominado mayoritario negro (de ambos sexos), siendo el tráfico y la

2 En el presente trabajo no se hace referencia a la población de inmigrantes caboverdeanos residentes en la Argentina, acerca de la misma se pueden consultar otros trabajos de la autora. 
explotación de mano de obrar esclava el gran pilar sobre el que se sostiene esta estructura.

Los portugueses provenientes fundamentalmente de Algarves, Alentejo, Madeira pertenecían a variados estratos sociales como por ejemplo: sacerdotes, funcionarios administrativos, comerciantes, agricultores, artesanos y los enviados por delitos, marginales y prostitutas (Carreira 1972, 1977; Davidson 1998), muchos de ellos que llegaban a estas tierras seducidos por las ventajas que les otorgaba la corona portuguesa a través de concesión de privilegios en el comercio de esclavos con la costa africana, particularmente con Guinea, esclavos que no sólo poblaron las "deshabitadas islas" sino fueron llevados a distintos destinos en América. Los hombres que salieron de Portugal, en general lo hicieron solos, muy rara vez emigraron junto a su familia. Estos hombres, en su mayoría, se unieron a la mujer negra con la que tuvieron hijos, constituyendo el punto de partida del intenso proceso de miscegenización que se produce en el archipiélago y que aún hoy prosigue, como parte de un habitus constitutivo, en las islas y en la diáspora.

La mujer negra y esclava, según Roger Bastide, fue objeto de una triple dominación: de raza, por el hecho de ser negra; de casta, por ser esclava (además de reproductora de mano de obra) y de sexo, por ser mujer en un régimen donde el que ejerce la hegemonía es el hombre ${ }^{3}$. Dominación también construida y reforzada por la Iglesia Católica, de fuerte incidencia en las sociedades mediterráneas, donde la mujer "debe" como precepto fundamental obediencia al marido-hombre, quien posee el legítimo derecho hasta de pegarle, tanto a ella como a los hijos.

La relación hombre blanco-mujer negra estableció una asimetría particular entre hombres y mujeres, enmarcada en una ideología patriarcal, que vendría a tener una influencia definitoria en la configuración de la familia y de las relaciones en su interior.

¿La familia o las familias caboverdeanas?

Smith (1962) al discutir las distinciones conceptuales entre grupo doméstico y familia, cita el bien conocido Notes and Queries... como

3 R. Bastide (1974), citado por Lopes Filho (1996:147). Entre otras autoras, que discuten la relación de raza, sexo y género ver V. Stolke (1974 y 1999) y Fernández-Rasines (2001) 
ejemplo de la complejidad y de la ambigüedad del concepto de familia que, así como el parentesco en general, son "manipulables, por grupos e individuos de acuerdo a sus intereses" (Woortmann, 1987:60)..

Así como Klaas Woortmann(1987), en su estudio de los negros y mulatos de condición social baja de Salvador (Bahia, Brasil), habla de dos modelos, uno ideal y otro de la praxis (definido como un modelo operacional adaptado a la difícil situación socioeconómica de la mayor parte de los pobladores), los cuales también son aplicables para interpretar la situación entre los caboverdeanos.

Para ello, el modelo analítico "debe retener la existencia y la actuación recíproca de esos dos modelos culturales, así como la ambigüedad que resulta de su manipulación diferencial por hombres y mujeres en circunstancias específicas. Preciso es también comprender que, para muchos, el modelo ideal es un ideal desistido, y que la praxis de la vida impone lo que podríamos llamar una ideología realista"(1987:59). Por lo tanto, es conveniente iniciar el análisis esclareciendo lo que significa familia para los caboverdeanos, los cambios acontecidos en dicha conceptualización y también cómo ha sido definida por los antropólogos que se han dedicado a su estudio.

¿En criol cuál es el término para referirse a familia? "Hay una gran diferencia 30 o 40 años atrás entre el criol fundo ${ }^{4}$ y el criol del que ha ido a la escuela. Hay una diferenciación entre los iletrados y los letrados, "é gent de

El criollo fundo es definido por Baltasar Lópes (1984) como o mais fiel ao tipo tradicional y lo opone a un sermo politus de uso generalizado entre las personas ilustradas, implicando así un acceso a la escolaridad o mayor contacto con la lengua portuguesa. También en el mimeo del I Coloquio Lingüístico sobre el Crioulo de Cabo Verde, realizado por el Ministério da Cultura (1979), Amália Andrade y Dulce Fanha, inspiradas en B. Lópes, hablan de crioulo-fundo como el más apartado del portugués (lengua base), opuesto al crioulo-levinho, más aproximado a sus estructuras, de uso generalizado en personas ilustradas. Meintel, D. (1975) en su articulo Creole dialect of Island of Brava, observa que el criollo fundo se utiliza en situaciones de intimidad y el criollo leve o levinho en situaciones de respeto más formales. 
fulano de tal" no hay un término 'familia de fulano'. Hoy modernamente $^{5}$ se dice familia".

En Ensayo de Análisis de la organización familiar caboverdeana (Maffia, 1994), señalamos la presencia de dos "ideas" de familia con las que se manejaban los caboverdeanos. Una de ellas, restringe la familia a aquellos parientes con los que se tiene lazos consanguíneos, no importando cuán distantes sean esos lazos, lo que se sintetiza en una frase que los informantes usan a menudo:

"Primo, é de sangue, mulher muda".

Esta modalidad es observada actualmente por Lissa Åkesson (2004:113) en la isla de Santiago, afirmando: "Relatedness through the familia is open to everyone seen as related through blood. Hence, affines do not belong to the familia. When I asked people about the status of affines, they referred either to lack of 'blood ties' or to the instability of couple relations. It was clear that to most São Vicentians, the networks made up of people regarded as kin provide much more economic and social security than relations to affines. The familia last, while couple relations are transitory".

La otra idea de familia hace referencia a aquel grupo constituido por el padre, la madre, los hijos y otros parientes, como abuelos, primos, tíos, etcétera, hasta amigos ${ }^{6}$, para los cuales se trabaja y que constituyen una compañía, un apoyo indispensable y una riqueza, la que correspondería a lo que los antropólogos designan, aunque no estrictamente, como familia ampliada. A ella se suman aquellos vínculos que se establecen por la convivencia, es decir, en el vivir-con-el otro, en un mismo espacio, compartiendo un mismo alimento y el afecto de los padres (principalmente el de la madre). Esos lazos permiten la constitución de una nueva relación que, sumada a las otras relaciones (consanguínea y afinal), dan forma a una organización familiar diferente, aquella que,

5 El subrayado en nuestro.

6 Woortmann, K. (op.cit.:149). "relaciones que incluyen solidaridad -amigos, vecinos, colegas, etc.”. 
como vimos, se presenta mayormente en los estratos socioeconómicos más bajos.

"A veces más que el parentesco entre los caboverdeanos, lo que hace es el trato, el cariño con que se quiere a ese primo, que a veces un primo de segundo y tercer grado pero se trata con tanto cariño que llega un momento que uno no sabe si son hermanos o hijos, no sé, es el cariño más que nada”. (Lila, 65 años, nacida en São Vicente).

La informante, que vino a la Argentina cuando tenía aproximadamente 14 años, se refiere al Cabo Verde de su niñez en la década de 1940.

Todo reafirma que, más allá de los lazos parentales, independientemente

de la distancia genealógica, están las relaciones de afecto ("de sentimiento"Woortmann, 1987:149), de las que se espera el mayor grado de solidaridad y reciprocidad, lazos que caracterizan a la familia "tradicional" como opuesta a la "moderna" (Bestard, 1998). Estas relaciones, según Bourdieu (1977 y 1991), constituirían el "parentesco práctico", que comprende no sólo el conjunto de relaciones genealógicas en funcionamiento, sino también, el conjunto de relaciones no genealógicas que se pueden movilizar para las necesidades ordinarias de la existencia ("relaciones prácticas").

"Cada grupo tienda a conservar, mediante un continuo trabajo de mantenimiento, una red privilegiada de relaciones prácticas"(Bourdieu, 1991:277), esas relaciones son las que permitirán catapultar a los posibles emigrantes hacia fuera, insertarlos y sostenerlos, sobre todo en la primera etapa, en sus nuevos lugares de residencia.

Los antropólogos Lópes Filho (1996) y Martins Jesuino(1996) coinciden en afirmar que "No se puede decir que exista en la sociedad caboverdeana un sólo tipo de familia que la caracterice, por el contrario, estamos en presencia de una sociedad en la que existe una multiplicidad de formas de vida familiar, pudiendo, en algunos casos y en determinadas ocasiones, tener un predominio de cualquier tipo de familia, lo cual no nos permite generalizar un modelo patrón"(Lópes Filho, 1996:79 y Martins Jesuino, 1996: 95).

Sin embargo, no acordamos con los autores mencionados cuando sostienen que existe una multiplicidad de "tipos" (ni de familias ni de 
grupos domésticos), sino, más bien, habría un modelo flexible, al estilo del modelo analítico de Klaas Woortmann, (engendrado por un habitus), que genera soluciones, o "una infinidad de esquemas particulares directamente aplicados a situaciones particulares" (Bourdieu, 1996) Aunque a la "infinidad" a la que Bourdieu hace alusión le pongamos un límite relacionado con el ciclo de desenvolvimiento del grupo doméstico y con la "calidad de vida" que deviene de una situación de clase, en el sentido que Bourdieu da al término .

Si bien, por un lado, persiste en todo el grupo caboverdeano un ideal de familia (la "blanca" monogámica) que se presenta en conformidad con los valores dominantes ${ }^{7}$-esto es, los ideales de la elite-, la experiencia de la "miseria" lleva a la población estudiada a la elaboración de ese modelo alternativo (el de la praxis). En los puntos siguientes examinaremos ejemplos esclarecedores de lo anteriormente expuesto.

El grupo de investigadores dirigidos por el caboverdeano Luis De França (1986 y 1992) cuando relevaba la temática familiar en su estudio sobre la inmigración caboverdeana en Portugal, expresó las dificultades que tuvieron para poder definir familia en el orden del discurso, ya que por ejemplo, la misma palabra familia comprende conceptos con amplitudes diferentes:

"A lo largo de toda la narración la familia restrita e alargada surge como referencia, como soporte, como objetivo de vida, pero cuando preguntamos más directamente el concepto de familia, (esa abstracción lejana tan próximamente vivida) la cuestión no es claramente entendida si no por aquellos que tienen un mejor nivel cultural" (De França ,1986: 8).

7 Rowland, R. (1989:120). "De los análisis hasta ahora publicados -y que se refieren casi todos a Portugal- es ya posible extraer dos conclusiones: la primera es que en el suroeste de la península (Algarve, Alentejo) el sistema familiar parece haber sido determinado por reglas de residencia neolocal, mientras que en el noroeste (norte de Portugal, Galicia) el sistema se nos aparece marcado por la residencia patrilocal. Estos dos sistemas, caracterizados por familias nucleares en el sur y por familias troncales en el norte, corresponden a zonas donde la edad media al matrimonio de las mujeres es, respectivamente, más baja y más elevada. En segundo lugar, dichas estructuras familiares parecen manifestar más allá de las fluctuaciones de corto plazo, una gran estabilidad en el tiempo: desde el siglo XVIII hasta mediados del siglo XX, encontramos sistemas basados en la familia nuclear en el sur y en la familia troncal en el norte". 
Y prosigue: "La familia para el caboverdeano parece incluir múltiples lazos de solidaridad y cooperación. Si en primer lugar engloba todos los parientes por sangre y afinidad ella también puede englobar los autóctonos de la misma isla. Familia y amigos se confunden en un sentido de entreayuda ${ }^{8}$ que se manifiesta en diversas situaciones -apoyos en la construcción de la casa, préstamos, contactos para buscar trabajo, convívios, etc."( 1986: 8).

Si la consideramos en términos de la antropología clásica ${ }^{9}$, la familia elemental "...(o familia nuclear o aun familia restringida) es formada esencialmente por un hombre, su esposa y sus hijos (...) Algunos autores prefieren hablar de familia conyugal o de familia consanguínea para indicar o señalar que la familia nuclear es encarada bajo el ángulo de una $\mathrm{u}$ otra de las relaciones elementales de parentesco que pone en juego, a saber, la relación de casamiento o la relación de consanguinidad (real o ficticia) que une los hijos no casados a sus padres" (Augé, 1978: 49). La familia nuclear es poco numerosa en la sociedad caboverdeana (Lopes Filho, 1996 y Braz Dias, 2000), pero sobre todo en los estratos sociales más bajos y en las zonas rurales; basándonos en la propuesta de Woortmann(1987), constituye para la mayor parte de la sociedad caboverdeana el modelo ideal desistido, aunque actualmente se asiste a una mayor expansión a consecuencia de las transformaciones que se operan por influencia de la emigración ${ }^{10}$.

8 Djunta mon en criol: juntar las manos, presente no sólo en poblados africanos sino también en zonas rurales de Latinoamérica.

9 Para Radcliffe-Brown, A. (1972) el origen del parentesco está en la familia elemental y es justamente por eso que ella es "elemental, en la misma se constituyen las tres relaciones básicas: la relación de filiación, la relación conyugal y la relación de seebling-ship".

10 Braz Dias, J. (op. cit); Martins Jesuino, B. (op.cit).

En 1989 efectuamos una entrevista a la Dra. Emilie Santos durante su visita a la Argentina; ella es una médica caboverdeana, miembro del Proyecto maternoinfantil y planeamiento familiar en Mindelo (São Vicente), realizado conjuntamente con la organización sueca Rädda Barnen entre 1978 y 1987. Nos relató que, frente a la pregunta: cómo debería ser la familia ideal, la respuesta más frecuente de las mujeres sanvicentinas fue: de 3 hijos y 2 adultos. 
Según Carreira, "no méio rural (e mesmo na zona suburbana) a familia nuclear, legítima à face do conceito europeu, é mais rara. Na realidade predomina ali uma espécie de familia extensa, de tipo específico" 11.

Veremos en qué consiste esa "especie" de familia extensa aludida por Carreira. Consideramos la familia extensa como "resultado de la extensión, en el tiempo por intermedio de lazos de casamiento, de las relaciones entre padres e hijos" auge 1978 51, a la que algunos autores como René Konig (1971), llaman ampliada, "muy frecuente en Cabo Verde" según las investigaciones de Lópes Filho (1996: 80).

Más que ampliación de las relaciones a lo largo de varias generaciones, tenemos una ampliación colateral primos-primas, tías-tíos y otros parientes. Además, como han aludido los autores mencionados, no tiene que ver solamente con los lazos de consanguinidad o de alianza, sino que se define en función de diversos criterios, pudiendo incluir personas entre las que no existen relaciones de parentesco. Una de estas relaciones es la que denominan de criança (de crianza), nha mai de criação (mi madre de crianza) y fidj de criação (hijo de crianza).

Vemos aquí el caso de Marituda, quien se refiere a la década de 1920, en la que aún se encontraba en Cabo Verde:

"Pongamos se crió una señora, se llamaba Francisca cuando entendí la encontré en la casa de mi abuela. No se distinguía que no era hermana de mi mamá, era igual, igual que fuera hermana de mi mamá y tenía los padres mismos, casa, su bienestar con mis abuelos y se quedaban y se quedó en la casa de mis abuelos...había otro muchacho que se llamaba Alfredo y se crió allí, crió como tal cosa, en casa de los padrinos. El padrino allá es un padre y la madrina es una madre". (Marituda, 91 años, nacida en Santo Antão).

En un período posterior, cercano a los años treinta, otro informante nos relata:

"Yo con ellos no tengo hermandad de sangre, eso es lo que es la familia caboverdeana para comprender, nosotros nos

11 Carreira, A. (1984:155), el subrayado es nuestro. 
tratamos como si fueran hermanos particularmente los más chicos, los mayores no, porque los mayores nunca estuvieron juntos, pero de Pedro para abajo mi mamá los crió igual que a mi, ella los tomó de chico de seis o siete años... y resulta que criamos juntos seguimos una relación familiar como hermanos... porque yo nací antes que todos ellos, cuando mi padre era soltero, entonces no hay una relación fluida (con los otros hermanos) como con estos hermanastros o "hermanos de crianza" como decimos nosotros, no sanguíneamente no tenemos nada, nada, pero hay toda una relación de crianza, comimos en la misma mesa, dormimos en el mismo catre, o en la misma esterilla, como era costumbre en Cabo Verde en aquella época, de modo que la relación de familia en Cabo Verde es un asunto muy complejo". (João Serafim, 78 años, nacido en Santo Antão).

Si bien en el plano del modelo (tradicional del parentesco), en la categoría "hermano", asociada a la sangre ("hermandad de sangre", "sanguíneamente no tenemos nada") se reconoce la distinción, en la práctica no viven la distinción ${ }^{12}$.

Otro caso interesante es el de la madre de Marta quien antes de migrar en 1921 a la Argentina, tuvo tres uniones libres, de la primera nacieron dos hijas. Su marido murió muy joven y ella se unió por un breve tiempo con un hombre del cual tuvo una hija que tiene sólo el apellido materno; el partenaire migró y no regresó nunca más a Cabo Verde. Ella se vuelve a unir con un tercer hombre y tiene dos hijos varones a los cuales el padre sí les dio su apellido. Los cinco hijos vivían junto a ella y al "padre" (biológico para unos, social para otros, según nuestra distinción). Cuando realizamos el árbol genealógico se produjo en principio una gran confusión porque, una de las hijas nos dijo que eran cinco hermanos. Recién cuando fueron dichos sus apellidos y al preguntarles

12 Como de alguna forma advierte Leach, E. (1964:26-27) en la Introducción de Sistemas Politicos de la Alta Birmania, refiriéndose a los modelos construidos por los antropólogos, "Lo que resulta mucho más difícil es el relacionar dicha abstracción a los hechos del trabajo de campo empírico". 
específicamente si eran hijos del mismo padre y de la misma madre, aclaró quiénes eran hijos de un padre y quiénes de otro.

Pensando la familia en términos de Bourdieu, como soluciones engendradas, veremos qué familia es la que se constituye en la "camada" $" 13$ social más baja:

"Si yo te digo de los míos, era un despiole, porque además de la hermana de mi papá que tiene siete hijos que están todos vivos, el marido, ella, yo, que no era hijo pero estaba como uno de los hijos más, vivía en la misma casa, a parte de eso otra familia que son parentesco, vendría a ser primo segundo que allá se va...el hecho de ser primo, no un primo directo ${ }^{14}$, yo por ejemplo era primo directo con los hijos de la hermana de mi papá que vivíamos en la misma casa, pero yo incluso crecí como un hijo más, prácticamente me criaron de chiquito, yo era un hijo más....vivía un montón de gente, son todos familiares, en la casa de mi mamá, siempre estoy hablando de mi mamá la hermana de mi papá y a veces llegaba un momento que éramos como veinte...te hablo de una casa de pobre como nosotros, no éramos ricos, éramos pobres..." (Virgilio, 65 años, en referencia a su niñez en Cabo Verde en la década de1940).

Con respecto a la residencia si bien el modelo ideal indica que los recién casados, o unidos, deberían ir a vivir a una nueva residencia (neolocalidad), el modelo de la praxis señala "vivir donde se pueda y como se pueda", como claramente expresa Manuel en el ejemplo anterior. La familia, en la camada mais abastada, también incluía parientes lejanos, generalmente "pobres", ahijados, además de sirvientes. Los

13 El término "camada social" es utilizado para referirse en forma general a la clase social ; para nombrar las dos principales "camadas", utilizan estas denominaciones, que denotan múltiples dimensiones ; por un lado, "los ricos", "la elite", "la clase abastada", "los que tienen linaje", "la gente blanca" ( a gent' branc'), "los letrados" y por el otro, "el pueblo", "los pobres", "la gente negra" (a gent' pret'), "los que no tienen ningún linaje", "los iletrados".

14 Se refiere a primo hermano. 
hombres, jefes indiscutidos de estas familias tenían con frecuencia varias mujeres "fuera del matrimonio", con las que podían o no tener hijos, reconocidos o no.

Hoy podríamos hablar -como lo hace Lisa Åkesson (2004) para Cabo Verde y Bela Feldman-Bianco (1992) con respecto a las familias portuguesas emigradas a los Estados Unidos-, de "estructuras familiares (inclusive la formación de unidades domésticas) transnacionales", a través de las cuales las decisiones de la vida cotidiana se extienden, y dependen de familiares que viven entre dos o más países, el de origen, y otro/s. Para Feldman-Bianco esta familia transnacional emergente "no es solamente manufacturada a través de tradiciones familiares y fotos, sino por una migración de retorno que implica vivir simultáneamente en los dos países haciendo uso de los derechos a la doble ciudadanía"(FeldmanBianco, 1992: 14)

En relación a la caracterización de la familia en Cabo Verde, el cuadro se complica por la presencia de arreglos poligínicos. En este punto, como advierte Lévi-Strauss (1986: 65), es conveniente "mostrarse prudente respecto del tema de la familia polígama, es decir, aquella donde prevalece tanto la poliginia -unión de un hombre con varias mujerescomo la poliandria -unión de una mujer con varios hombres-. Estas definiciones sumarias tienen sus matices. "A veces, la familia polígama consiste en varias familias monógamas yuxtapuestas: el mismo hombre es el esposo de un cierto número de mujeres, cada una establecida con sus hijos en una morada separada. Se lo observa a menudo en África”. Más adelante, el autor sostiene que la práctica poligámica depende de ciertas condiciones, por ejemplo, la supresión voluntaria de los niños de uno de ambos sexos, la esperanza de vida diferente el según sexo, las sociedades fuertemente jerarquizadas, en las cuales una clase determinada se atribuía mayor número de mujeres, el capital económico con que se cuenta, como ocurre en algunas sociedades africanas donde es necesario ser rico para tener muchas mujeres.

El estudio demográfico de Carreira (1977) utilizado posteriormente por la mayoría de los antropólogos que analizaron el tema, señala, en primer término, una diferencia muy significativa entre el número de mujeres 
respecto al número de hombres, fundada en la emigración masiva de los hombres durante décadas ${ }^{15}$.

Esta situación es frecuentemente aludida en los relatos nativos, cuando intentan explicar la poligamia. En primera instancia, no dudan en afirmar que tal costumbre no está legalmente permitida en el país, pero que, a pesar de eso, "existe y acontece con gran frecuencia" ". Esto fue referido por varios informantes, pertenecientes a distintos tiempos desde principio del siglo XX, hasta la década de 1950, épocas a las que pertenecen los siguientes entrevistados:

“...era siempre mal visto en Cabo Verde y el hombre que tuviera más de una mujer era censurado por los demás" (Sebastião, nacido en São Vicente).

"Claro es mal visto pero todo el mundo habla por debajo, nadie abre la boca para acusarlo, para decir, Usted es un irresponsable" (Adelina, nacida en São Vicente)

"Usted como antropóloga y como mujer todas esas cosas, las costumbres de Cabo Verde, las va a saber. Nosotros muchas veces las escondemos, pero a usted no se las podemos esconder". (Mariazinha, nacida en Santo Antão)

Algunas de las explicaciones emic están fundadas en la naturaleza del hombre $^{17}$ (pero no de la mujer) y, aunque la mujer no las acepta -

15 Es necesario señalar que, en los trabajos sobre población en Cabo Verde, no se menciona el descenso en el número de hombres ocasionado por las muertes de los marinos que, sin lugar a dudas, de acuerdo a los medios precarios de la época debieron ser muchas. Se contabiliza el descenso debido a las migraciones, en relación a la posibilidad de enviar remesas, tema que ha sido objeto de numerosos estudios sociológicos y socio-económicos.

16 Braz Dias, J. (op. cit: 151) sostiene, para el caso particular de la isla de São Vicente, que "muchos hombres mantienen relaciones sexuales con más de una mujer al mismo tiempo".

17 Åkesson, L. presenta en su tesis similares hallazgos y afirma: "El hombre caboverdeano desea conquistar muchas mujeres, lo que esto significa que pueden sacar algo bueno de la vida. Tener muchas mujeres también implica que los hombres pueden demostrarse a sí mismos y a los demás, que pueden ser exitosos 
podríamos decir, por una explicación cultural: en este caso "el feminismo"-, frente a lo que pertenece al orden de la naturaleza "poco y nada se puede hacer".

"Usted sabe que el hombre naturalmente, aunque la mujer dice que no, el feminismo, naturalmente fue bígamo, y más las circunstancias de Cabo Verde, donde hay muchas más mujeres que hombres porque los hombres emigran; entonces los hombres que están tienen un hijo allá , otro por otro lado." (Orlando, 71 años, nacido en São Vicente).

A esto se suma el ya citado dato demográfico: hay más mujeres que hombres ${ }^{18}$.

La falta de hombres en Cabo Verde es representada risueñamente en esta popular coladera caboverdeana cuya traducción del criol es la siguiente $^{19}$ :

(...). El hecho que los hombres 'quieran' tener más de una compañera es visto, tanto por los hombres como por las mujeres, como algo inherente a la naturaleza masculina.”(2004:105). "Las nociones de masculinidad están fuertemente acopladas a la actividad sexual y el comportamiento polígamo es un elemento central del ser 'un hombre en serio'. Pero la monogamia de una vida entera tampoco es esperada para las mujeres. Hay una importante diferencia, sin embargo, mientras que es visto como "natural" para los hombres mantener más de una relación simultáneamente, es aceptable para las mujeres entrar en una nueva relación conyugal sólo cuando están solteras"(2004:102).

18 En una entrevista personal con el investigador noruego Jörgen Carling, en noviembre de 2005, él nos manifiesta que la diferencia numérica entre mujeres y hombres se ha constituido en la actualidad en un mito, ya que no se corresponde con los datos demográficos. Sin embargo, hasta 1998, según las proyecciones demográficas realizadas por el gobierno de Cabo Verde, “...la situación de la mujer es marcada por el fuerte desequilibrio de la relación de masculinidad, con 91,3 hombres por cada cien mujeres, debido esencialmente a la predominancia de la emigración de los hombres" (Dirección General de Estadísticas, 1998:2).

19 Esta coladera fue escuchada en la casa de un informante en los comienzos de la investigación, en la década de 1980; al requerirle, en años recientes, la versión original en criol, lamentablemente no pudo hallarla y, a pesar de consultar con distintos informantes, ninguno la conocía, razón por la cual no pudimos incluir el texto en ambas lenguas. 
"Yo fui a la ribera a buscar agua en la fuente

las mujeres se juntaron sobre mí

dieron conmigo en el suelo

y rompieron mis pantalones

para mirar el "pau de lume" 20

mujeres no me enfrenten

el "pau de lume" es mío

y ya tiene su dueño,

mujeres no me enfrenten

porque el "pau de lume es mío"

y ya tiene su dueño.

Pero gente que afronta

El "pau de lume" de la tierra

Es mujer con falta de hombres

Oh mi gente, qué desesperación en mi tierra

Las mujeres con falta de hombres"

La cuestión de género se hace evidente en cuanto que el pau de lume tiene dueño y no dueña $\mathrm{y}$, por otro lado, en la reiteración del género vinculado a la tierra, referida en toda su literatura y música popular como "madre tierra". También es interesante señalar la expresión retórica con la que se compara la tierra caboverdeana, tierra pobre, con falta de agua, de alimentos y también de hombres, con la "mujer con falta de hombres".

La explicación dada por nuestro informante es:

"La inmigración es tan grande, todos los varones que pueden se van, entonces las mujeres se tienen que repartir los que quedan". (Teófilo, 75 años, nacido en Santo Antão)

Eugenio Tavares, poeta caboverdeano, también alude a esa situación en las Sátiras, escritas en 1924.

Há nove mil robustos habitantes
Na nossa ilha. Desses tantos seres

Hay nueve mil robustos habitantes

Se ve que mais de seis mil são mulheres,

Se ve que más de seis mil son mujeres,

20 Pau de lume: palo de fuego, es una metáfora para indicar el pene. 
Desses tres mil só dois são celebrantes; Dando-se que, para cumplir deveres De esos tres mil sólo dos son festejantes; Do Bíblico crescei, e mais misteres, Dándose que, para cumplir deberes

Nao há, de modo algum, homens bastantes! No hay, de modo alguno, hombres bastantes!

Uma sala de baile, a Brava! A roda,

Se sentam mais de cinco mil madamas

Una sala de baile, la Brava! La ronda,

Se sientan más de cinco mil mada,

Que la danza atrae, los corazones en llamas.

Se cada dama não ceder seu par,

(Como se sabe que é de lei, e é moda)

Si cada dama no cede su par,

Tres mil mujeres quedan sin danzar.

Nuevamente aparece, en este discurso de raigambre más popular, la referencia al número de hombres respecto del de mujeres. Del mismo modo lo testimonia este informante:

"Sabe lo que ocurre, hay muchas mujeres, posiblemente hay más mujeres que hombres y eso no hace falta que se lo explique, está todo dicho". (Víctor, 55 años, nacido en Santo Antão).

La Sátira de Tavares también hace alusión al mandato bíblico de crecer y multiplicarse, al cual hombres y mujeres deben obedecer.

En las narrativas encontramos otras explicaciones, en el orden de la cultura, como la influencia de las tradiciones, tanto africanas como portuguesas, con mayor énfasis en las africanas y, particularmente en la religión musulmana, argumento -sin lugar a dudas- surgido en los sectores intelectuales de Cabo Verde y popularizado en los sectores menos escolarizados.

"Esa es una dualidad que yo le voy a diseñar en este momento, dualidad por lo siguiente: el caboverdeano desciende, lógicamente, una parte del africano, ochenta por ciento africano y en el África, son casi todos... el África es musulmana y los musulmanes pueden tener la cantidad de mujeres que quieran, entonces por ese lado, el caboverdeano arrastra ya esa costumbre. Por otro lado, el 
portugués que venía como colonizador, si lo podemos llamar así, también venía soltero y tenía un montón de sirvientas, ya en nuestros tiempos o en otros tiempos, entonces tenía hijos con varias mujeres. Entonces se mezcla esa parte musulmana y esa parte colonial y trae esa costumbre que poco a poco va desapareciendo y se sumó la disparidad entre los sexos". (Adriano, 76 años, nacido en São Vicente).

“...tengo un primo que a veces habla, lo justifica diciendo que somos descendientes de africanos, en las tribus africanas el cacique tenía varias mujeres, pero es herencia de los portugueses también, yo conozco casos y sé de la historia de Cabo Verde que los portugueses usaban ese mismo sistema... es una cultura celta parece...! (Natalia, 62 años, hija de caboverdeanos de São Vicente).

"El hombre caboverdeano es muy machista...El hombre caboverdeano quiere ser el superhombre, quiere tener cincuenta mujeres, tiene todavía el espíritu africanista, no es uno solo que tiene dos, tres mujeres. O tiene la mujer, la esposa e hijos fuera..." (Celia, 46 años, hija de caboverdeanos de São Vicente).

Según Lópes Filho "La tendencia a la poligamia, institucionalizada en las uniones libres es consecuencia de este comportamiento de los señores que hacían gala en ostentar numerosas amantes e hijos bastardos, no teniendo la poligamia, por lo tanto, origen en las sociedades tradicionales africanas" (Lopes Filho, $1996: 70$ )

Sin descartar, que en este tipo de prácticas resignificadas en el nuevo contexto, haya tenido participación la tradición mediterránea -sobre todo en la elite-, no podemos dejar de considerar el pasado africano de las poblaciones de base del archipiélago. Son numerosos los estudios que testimonian, en las sociedades del Caribe y de América, la presencia de este tipo de prácticas o de uniones $^{21}$. Trajano Filho (1998), en un estudio

21 "Según los datos de Eurostat del 1 de enero de 1993, había en el espacio de la Unión Europea 2.699,2 millones de africanos de los cuales, según algunos, el $25 \%$ son polígamos. Jacques Barou, sólo para Francia, habla de 320.000 
sobre la sociedad criolla de Guinea Bissau, marca la existencia de una fuerte tendencia poligínica, que aparece bajo la forma de la costumbre kasa dus (literalmente "casa dos").

Juliana Braz Dias, quien investigó sobre la situación familiar de los caboverdeanos en la década de 1990, refiere que la mencionada costumbre "es el resultado de una negociación entre principios contradictorios-lusitanos y africanos- que participan en la formación de la sociedad criolla" (Braz Dias, op.cit.: 98). Si bien, siguiendo a la autora mencionada, podemos encontrar la contradicción en el nivel del modelo ideológico, sostenemos que, como hemos dicho anteriormente, en el modelo de la praxis podremos hablar de un acoplamiento estructural entre ambos.

Tanto las prácticas como los modos de argumentar construidos por los distintos estratos sociales caboverdeanos son generadas/producidas por el habitus, inculcado a través de la educación familiar, particularmente en manos de las mujeres y reforzado por instituciones como la Iglesia, la Escuela y el Estado. "Los dominados aplican categorías construidas desde el punto de vista de los dominantes a las relaciones de dominación, haciéndolas así ver como naturales"( Bourdieu , 1999 :42).

Recordando los clásicos conceptos definidos por numerosos antropólogos, entre ellos Marc Augé (1978), quien trabajó por muchos años en Africa, la familia compuesta o poligámica es aquella que resulta del casamiento plural, la poliginia o la poliandria. El primer término refiere a un grupo de dos o más familias nucleares emparentadas entre sí a través de un hombre que desempeña el papel de único marido (o padre); en realidad, se trata de dos o más unidades matricéntricas (constituida por una madre y sus hijos) ligadas, por intermedio de un lazo conyugal, a un mismo hombre. El segundo, la familia poliándrica es la constituida por una mujer, sus maridos y sus hijos. Esta última es muy poco frecuente y prácticamente inexistente en África.

Según Lévi-Strauss (1984:18), "un buen número de las llamadas sociedades polígamas son auténticamente tales, pero muchas otras establecen una marcada diferencia entre la primera, estrictamente la única y auténtica esposa, dotada con todos los derechos que concede el

africanos de los cuales 130.000 están sujetos a prácticas poligámicas". Tomado de Lopes, P. (1994:32). 
status conyugal, y las otras que en ocasiones son poco más que concubinas".

Para el caso caboverdeano, hablaremos de quasi poligamia (lo que Finan y Henderson (1988: 94) llaman informal polygyny $\mathrm{y}$, más específicamente, de quasi-poliginia, en virtud que no existe un casamiento plural oficialmente reconocido, sino que hay un casamiento (un matrimonio) entre un hombre y una mujer, formalizado por vía civil y/o religiosa (en algunos casos dependiendo de la clase social), y otras uniones de ese hombre ("fuera del matrimonio") 22, aceptadas consuetudinariamente, en general conocidas por todos y no exentas de conflictos. Carreira documenta una larga historia de lo que llama "poligamia de facto", practicada por los hombres blancos, cuyas uniones no matrimoniales o extramatrimoniales con mujeres de la clase más baja era, en general, de conocimiento público, toleradas por sus legítimas esposas (Carreira, 1977: 31 y Meintel, 1984: 111). En ambos estratos sociales era una costumbre muy frecuente pero, desde el punto de vista de los hombres de la élite, las mujeres fuera del matrimonio son consideradas amazias (amantes) y no son parte de su familia.

En este punto, acudiremos a la distinción realizada por Bourdieu (1991)

entre parentesco práctico y parentesco oficial, que nos permite comprender mejor las complejas relaciones parentales y la organización familiar en Cabo Verde.

Cada grupo tiende a conservar, sostiene Bourdieu, mediante un continuo trabajo de mantenimiento, una red privilegiada de relaciones prácticas, la que no comprende solamente el conjunto de relaciones genealógicas en funcionamiento. A este conjunto de relaciones no genealógicas, que se pueden movilizar para las necesidades ordinarias de la existencia, las llama: parentesco práctico. En otras palabras, el parentesco de representación $^{23}$ se opone al parentesco práctico, como lo oficial se opone

22 Carreira, A. (1972:457). "La libertad sexual del 'señor' blanco, en especial en la isla de Fogo, se ejerció siempre sin preconceptos de color o de clase, aunque con 'marcante' discriminación social". Cabe señalar que tener hijos es señal de autoridad, contribuye a legitimar la autoridad.

23 Bourdieu, P. (1991:279) “...el parentesco de representación no es otra cosa que la representación que el grupo se hace de sí mismo (...)”. Los subrayados son nuestros. 
a lo no oficial (que engloba a lo oficioso y a lo escandaloso), lo colectivo a lo particular, lo público (explícitamente codificado en un formalismo mágico o cuasi-jurídico) a lo privado, (mantenido en estado implícito, incluso oculto), el ritual colectivo (práctica sin sujeto susceptible de ser ejecutada por agentes intercambiables porque son colectivamente acreditados) a la estrategia (orientada hacia la satisfacción de los intereses prácticos de un agente o de un grupo de agentes particulares).

Así, cuando habla del matrimonio, distingue: "el parentesco oficial, uno e inmutable, definido de una vez por todas por las normas protocolarias de la genealogía, del parentesco práctico, cuyas fronteras y definiciones son tan numerosas y diversas como los usuarios y las ocasiones de utilizarlo. Es el parentesco práctico el que hace los matrimonios y el parentesco oficial el que los celebra" (Bourdieu, 1991: 277).

"La extensión del parentesco práctico depende de la aptitud de los miembros de la unidad oficial para superar las tensiones que engendra la competencia de lo intereses en el interior de la empresa indivisa de producción y de consumo, y para mantener las relaciones prácticas conformes a la representación oficial que de ellas se hace todo el grupo, que se piensa como tal grupo integrado; para acumular por tanto, las ventajas que procura cualquier relación práctica y los beneficios simbólicos que asegura la aprobación socialmente acordada de las prácticas conformes a la representación oficial de las prácticas, es decir, al ideal social del parentesco" (Bourdieu, 1991: 280).

Al referir estas categorías de análisis a la situación en Cabo Verde registramos que, en la clase mais abastada, se designa como esposa a aquella que es producto de un matrimonio oficial y es reconocida públicamente. El acto oficial y la nominación ${ }^{24}$ instituyen la frontera entre los casados y los no casados, entre los casados y los simplemente unidos, entre la esposa y la amante, la concubina o la rapariga, quienes oficiosamente son reconocidas, instituyendo de ese modo un "parentesco práctico".

24 Bourdieu, P. (1991:282). "El poder simbólico de los categoremas nunca se muestra tan bien como en el caso de los nombres propios, que, en tanto que emblemas que concentran todo el capital simbólico de un grupo prestigioso, son objeto de una competencia intensa...". 
"Ordinariamente como sobraban mujeres (...), el que tiene un cierto poder adquisitivo puede tener amantes". (Tito, 65 años, nacido en São Vicente).

"Lo mismo los portugueses tenían la mujer oficial y la mujer de afuera y el hijo de afuera..." (Pedro, 43 años, hijo de una caboverdeana nacida en São Vicente).

"Tenían dos casas, se llama casa de fora, la mujer sabía, los hijos del matrimonio iban juntos a la escuela con los otros”. (Dina, 77 años, nacida en Santo Antão).

Entre los pobres, la/s otra/s mujer/eres -que en el criollo fundo son llamadas raparigas ${ }^{25}$ - y sus hijos, son considerados parte de su familia o su familia, aunque, como veremos, muchas veces el hombre no puede mantenerlos.

En lo expresado por el profesor Aurélio Gonçalves (primera cita), observamos que la práctica de la poligamia es referida en relación a la gente del pueblo mientras que, para la clase más alta o la elite, se trataría de infidelidad, sobre todo referida a la mujer, teniendo como referencia el matrimonio monógamo ${ }^{26}$. Se percibe claramente que el sustrato africano "no influencia homogéneamente a toda la población"; en realidad no es

25 Trajano Filho, W. (1998:462), señala en su tesis sobre la sociedad creol de Guinea-Bissau: "Cumborsas o Kumborsa is another Kriol word used en this context to designate co-wife, the concubine or just a lover". Este término nunca fue utilizado por nuestros informantes caboverdeanos en la Argentina; ellos manifestaron que posiblemente sea de origen africano y utilizado en la isla de Santiago.

26 Åkesson, L. (2004:105), consigna que: "Los hombres que mantienen abiertamente una relación con diferentes mujeres declaran que ellos nunca aceptarían el mismo comportamiento de la compañera mujer, Yo la dejaría inmediatamente o Ningún hombre caboverdeano aceptaría eso" (...) "La deslealtad femenina es profundamente amenazante para los hombres ya que señala la pérdida de control y suele ser interpretada como un signo de impotencia. La mera sospecha de la infidelidad femenina se esconde detrás de la mucha y amplia violencia doméstica hacia las mujeres". 
considerado: cuanto más se aproxima a la elite, más se distancia de la presencia cultural africana.

"El caso de hombres con muchas mujeres, eso se daba en la gente del pueblo. Había hombres de la sociedad que tenían amantes en las mujeres del pueblo que ocasionaban conflictos serios con las esposas terminando muchas veces en divorcio. Las mujeres del pueblo muchas veces peleaban por el mismo hombre por cuanto se daban casos de hombres con varias mujeres en la misma localidad. El hombre las ayudaba según sus posibilidades. Ellas se conformaban y a veces se las tenían que arreglar solas...”.(Aurelio Gonçalves, escritor caboverdeano)

"La familia es casi igual, cuando gente de campo peor todavía (tener varias mujeres)... peor todavía (la gente de dinero) ...yo con el hombre donde vivía yo (en la isla de Fogo), en la ciudad tenía su señora, sus hijos oficiales...y ahí en el campo, el tipo vivía prácticamente porque ahí estaba la gente que le trabajaba y tenía otra mujer ...con hijos". (Bía, 69 años, nacida en Fogo).

"La mayoría de esta gente, de estos hombres, que son el nueve coma nueve, de estos hombres, si pueden sí las mantiene, las dos o tres, no sé, las mantiene si puede, claro si no puede...algunos que no, casi siempre si puede...". (José, 70 años, nacido en Santo Antão).

"Como son gente de dinero no les interesa nada, total pueden tener una, dos mujeres, hoy pueden tener una, otra mañana, lo que quiera...”. (María, 71 años, nacida en Santo Antão).

Muchas veces, el comportamiento de los hombres blancos se asemejaba al droit de seigneur, que permitía el fácil acceso sexual a mujeres consideradas socialmente inferiores, particularmente aquellas que se encontraban en posición de dependencia personal (por ejemplo, siervas, empleadas). 
Esta situación es retratada crudamente por el escritor caboverdeano Luis Romano ( $1975: 50$ ), en varias oportunidades, en la trama de su novela Famintos.

“-Vem cá para dentro, menina. Não te faço mal nem vou-te comer. Toma, isto é para ti. A mocinha olhava para a nota e ficava cheia de medo, estendendo a mão, receosa, seguindo como os olhos os gestos de Comerciante que lhe mostrava o canapé já como a molas partidas, onde o uso fizera uma cova.

Pelo amor de Deus!

Ela sentia-se levada por dois braços de ferro que a encaixavam no fundo do assento. Comerciante trancou a porta do escritório e desceu a esteira, voltando-se para a mocinha que tentava esquivar-se.

-Pelo amor de Deus.

Ela cambaleou e sem reacção entregou-se a Comerciante, com um desejo de comer a martelar-lhe as estranhas.

Satifeito o homem meteu-lhe uma nota entre os seios, a dizer-lhe baixinho

-Virás amanha à tardinha e guardo-te uma blusa de seda cor-de -rosa"

En una sociedad en que las jerarquías racial y de clase casi coincidían, los blancos del sexo masculino gozaban de una doble ventaja: no utilizaban sólo el nivel económico y social, sino también la supuesta superioridad racial como arma de seducción. Vulgarmente cuando las mujeres tienen hijos de piel más clara, a través de ligazones de ese género, se dice que "mejoran la raza" (compo-raza en criol) (Meintel, 1984: 111), como lo expresa con claridad nuestro informante.

"Manda a buscar la mujer blanca de Europa, muchos hacen eso, que van a buscar mujer, son grandes comerciantes, después van y traen, tienen el complejo de mejorar la raza... y tienen la amante caboverdeana o mestiza caboverdeana, la sigue manteniendo, han tenido hijos, los siguen manteniendo y traen la mujer a la cual le dirán, mirá que yo tengo hijos allá, pero la otra viene por la plata y le importa un pepino a lo mejor". (Canú, 76 años, nacido en São Vicente) 
También debemos considerar situaciones como la descripta por Klaas Woortmann para los pobres de Bahía, en que las mujeres, en determinados momentos de sus vidas alternan con varias parejas, "correspondiendo a lo que Freilich (1961) llamó, un tanto impropiamente, 'poliginia seriada' (y que podría ser igualmente llamada poliandria seriada)"( Woortmann ,1987: 127).

Las mujeres que comparten el esposo -que ejerce un papel de relevoconstituyen junto a sus hijos las llamadas "díadas" por Bernardo Bernardi (1978) o las "familias diádicas" según nosotros, una "unidad económica, residencial, ritual y social en torno a la mujer" (Lopes Filho, 1996: 110).

Estas díadas también son designadas familias monoparentales 0 incompletas, ya que puede tratarse de mujeres viudas, madres solteras o mujeres separadas de sus maridos por condicionamientos sociales y económicos (el caso de la emigración $)^{27}$, con sus hijos. En verdad, según (Lópes Filho,op.cit.: 107), “constituye, conjuntamente con las formas de familia más alargada, uno de los modos de vida familiar más generalizado en este archipiélago".

Las mujeres que tuvieron un hijo de solteras, son denominadas en criol, mai di fidju y la expresión pai-di-fidju es usada por las mujeres, para referirse a los hombres con quienes tuvieron o aún mantienen relaciones y que no resultó en casamiento formalizado, pero que tuvieron hijos con ellas.

Estas díadas (madre-hijo/s) muchas veces son producto de la migración de los maridos:

"La mayoría tenía su familia en Cabo Verde y les mandaban plata constantemente, casi todos los meses... y de vez en cuando los iban a saludar, otros no venían nunca y les mandaban guita, porque el caboverdeano es medio raro, capaz que se casaban, tenían un hijo, la dejaban de compra, se iba, estaba 27 años en Norteamérica y la mujer estaba en Cabo Verde con el hijo eso sí, todos los meses llegaba el dinero, el cheque de los dólares, todos los

27 Esta variante fue observada y descripta minuciosamente por Braz Dias, J. (2000), la familia conformada por la mujer que queda sola con sus hijos cuando su marido emigra. 
Cuando el cónyuge se ausenta, sobre todo por períodos extensos, algunas mujeres se quedan a vivir en la residencia materna o paterna, a fin de poder dejar a los hijos mientras trabajan, como es el caso de la Sra. de Ribeiro, inmigrante de casi 90 años, que se refiere a sus vivencias en Cabo Verde en la década de 1920 :

"Me fui a vivir en mi casa solita con mi marido ${ }^{28}$. Mi marido se embarcó. Cuando hacía cuatro años que estábamos casados mi marido se vino a la Argentina. Me quedé en mi casa. Pero mi padre no quería que me quedara solita con los dos chicos que tenía y me fue a buscar y me llevó a su casa. Me quedé en su casa hasta que mi marido se fue de acá. Mi marido estuvo 16 años acá en la Argentina. Cuando fue nos fuimos a vivir de nuevo en la casa que teníamos".

Juliana Braz Dias (2000) utiliza la noción de "espera", la que nos permite analizar algunas de las situaciones atravesadas por las mujeres de los emigrantes. Esta noción se configura inicialmente como una forma de control social sobre las esposas cuyos maridos están embarcados. En este caso, el marido de Joana emigra hacia la Argentina y no puede quedar sola: su padre, como en las sociedades mediterráneas, es el custodio de la honra familiar. A partir de esa condición de vigilancia extrema surgen las críticas de alguna parte de la población sobre la condición sumisa y resignada de las mujeres. Esa fase negativa es complementada con el valor de la honra y de la dignidad con el que las (algunas) mujeres construyen su subjetividad. Todo el discurso de estas mujeres, destaca Braz Dias, a pesar de la intensa actividad que desarrollan -ya que muchas son jefas de sus hogares-, enfatiza la posición pasiva de alguien que se mantiene a la espera del retorno del marido. Permanecen en Cabo Verde pensando su subjetividad solamente dentro de la relación con el marido emigrante

28 Residencia neolocal. 


\section{A modo de cierre}

Como planteamos al inicio, nuestra intención fue analizar la organización familiar en las islas de Cabo Verde. Para ello fue necesario, aunque tal vez muy brevemente, por el espacio que disponíamos, señalar algunos aspectos referidos a la organización social del archipiélago caboverdeano, basada en la vieja institución escravócrata.. Sobre todo hacer referencia a la constitución o al poblamiento de las islas caracterizado por un profundo proceso de mestizaje. Las tradiciones mediterráneas, por un lado y las africanas por otro, están presentes en la configuración familiar, marcando las relaciones y la dinámica al interior de la misma, tanto en el pasado como en el presente.

El modelo analítico de Klaas Woortmann, en conjunción con la noción de habitus de Pierre Bourdieu, nos permitió una mejor aproximación a la comprensión de la multiplicidad de representaciones y prácticas de la vida familiar caboverdeana, atravesadas por las dimensiones de clase social, raza y género.

\section{Bibliografía}

ÅCKESSON, L. (2004). Making a life. Meanings of migration in Cape Verde. Departament of Social Anthropology, Göteborg University. Göteborg.

AUGÉ, M. (director) (1978) Os Dominios do parentesco (Filiação. Alianza matrimonial. Residência). Edições 70. Lisboa.

BERNARDI, B. (1978). Introduçao a os estudos etno-antropológicos. Ediçoes 70. Lisboa.

BOURDIEU, P. (1977). Outline of a theory of practice. Cambridge: Cambridge University Press. (Trad. del francés al inglés de Esquisse d'une théorie de la practique).

(ed. castellana1991). El sentido práctico. Madrid: Taurus Humanidades.

(1996). Razões Prácticas. Sobre a teoria da ação. Campinas:

Papirus Editora. 
BRAS DIAS, J. (2000). Entre Partidas e Regressos: tecendo relaçoes familiaes em Cabo Verde. Tesis de Maestría. Universidad de Brasilia. Brasilia.

CARREIRA, A. (1972) Cabo Verde. Formaçao e Extinçao de uma sociedade escravocrata (1460-1878). Centro de Estudos da Guiné Portuguesa. Portgual.

(1977) Cabo Verde. Clases sociales, estructura familiar, migraciones. Biblioteca Ulmeiro No 9. Lisboa.

(1984). Cabo Verde. Aspectos sociais, secas e fomes do século $X X$. Instituto Caboverdiano do Libro. Lisboa.

DAVIDSON, B. (1988). As ilhas afortunadas. Um estudo sobre a Africa em transformação. Instituto Caboverdiano do Libro. Lisboa.

DE FRANÇA, L. (1986-1987) (coordinador del proyecto). Relatorios preliminares del Proyecto "Imigrantes Cabo-verdianos em Portugal". Mimeo. IED/CIDEC. Lisboa.

FERNÁNDEZ, G. (2002). A diluçao da África. Uma interpretaçao na saga identitaria cabo-verdiana no panorama politico (pós) colonial. Editora de la UFSC. Florianópolis.

FERNÁNDEZ-RACINES, P. (2001). Afrodescendencia en el Ecuador. Raza y Género desde los tiempos de la colonia. Ediciones Abya-Yala. Quito.

FINAN, T. Y HENDERSON, H. (1988). The logic of Cape Verdean Female-Headed Households: Social response to Economic Scarcity. En: Urban Anthropology. Vol. XVII. (1). 87-103.

KONING, K. (1971). "Familia”. En: A.A.V.V., Sociología. Meridiano. Lisboa. 
LEACH, E. (1964). Sistemas políticos de la Alta Birmania. Anagrama. Barcelona.

LEVI STRAUSS, C. (1986). Mirando a lo lejos. Emecé. Buenos Aires.

LOPES, B. (1984). O dialecto crioulo de Cabo Verde. Imprensa

Nacional-Casa da Moeda. Lisboa.

MAFFIA,M. (1994c). Ensayo de análisis de la Organización Familiar Caboverdeana. PROENE-CIC. Buenos Aires.

MEINTEL, D. (1984). Emigração em Cabo Verde: solução ou problema?En: Revista Internacional de Estudos Africanos. 2 (juniodiciembre). 93-120.

LOPES FILHO, J. (1996). Ilha de San Nicolau, Cabo Verde. Formação da sociedade e mudança cultural. 2 volúmenes. Secretaría Geral, Ministerio de Educação, Cabo Verde.

MARTINS JESUINO, B. (1996) Estilos educativos dos inmigrantes caboverdianos. Tesis de Maestría, Universidade Aberta. Lisboa.

RADCLIFF-BROWN, A. (1972). Estructura y Función en la Sociedad

Primitiva. Península. Barcelona.

ROMANO, L. (1975). Famintos. Nova Aurora.Lisboa.

ROWLAND, R. (1989). Sistemas matrimoniales en la Península Ibérica (siglos XVI-XIX). Una perspectiva regional. En: Pérez Moreda, V. y Sven Reher, D. (Eds.). Demografía histórica en España. Madrid: El Arquero. 72 a 137.

SMITH, M. G. (1962). West indian family structure. Seattle: University of Washington Press.

STOLKE, V. (1974). Racismo y sexualidad en Cuba en la Cuba colonial. Alianza editorial. Madrid. 
(1999). "Es el sexo para el género como la raza para la etnicidad?". En: Cuadernos para el debate No 6. Programa de investigaciones socioculturales en el MERCOSUR. IDES. Buenos Aires.

TRAJANO FILHO, W. (1998). Polymorphic Creoledom: the "creole" society of Guinea-Bissau. PHD dissertation in Anthropology. University of Pennsylvania. USA.

WOORTMANN, E. (1994). Herdeiros, Parentes e Compadres. Edunb, Brasil.

WOORTMANN, K. (1987). A familia das mulheres. Tempo Brasileiro en co-edição com o Conselho de DsenvolvimentoCientifico e Tecnológico. Rio de Janeiro. 